\title{
Alianças Estratégicas como Condicionantes do Desenvolvimento da Capacidade Tecnológica: o Caso de Cinco Empresas do Setor Eletro-eletrônico Brasileiro
}

\section{Strategic Alliances as Conditioners of Technological Capacity Development: Five Cases from the Brazilian Electro-electronics Sector}

Zandra Balbinot *

Ph.D. em Administração pela HEC-Montreal, Canadá. Professora Adjunta da UFPR, Curitiba/PR, Brasil.

Rosane Argou Marques Mestre em Administração pela UFRGS. Consultora na Diretoria de Inovação da ABDI, Brasília/DF, Brasil.

\footnotetext{
* Endereço: Zandra Balbinot

Universidade Federal do Paraná, Av. Prefeito Lothario Meissner, 632, Jardim Botânico, Curitiba/PR, 80210-170. E-mail: zbalbinot@gmail.com
}

Copyright @ 2009 RAC. Todos os direitos, inclusive de tradução, são reservados. É permitido citar parte de artigos sem autorização prévia desde que seja identificada a fonte. 


\title{
RESUMO
}

Mundialmente, as empresas são impelidas a construírem capacidades para fazer face ao momento de intensa competição. No caso do Brasil, a pressão pela abertura dos mercados e a internacionalização da concorrência têm impulsionado as empresas a buscarem formas alternativas para acelerar o desenvolvimento tecnológico. Propõe-se no presente trabalho examinar a questão de como as empresas brasileiras conseguem aumentar a sua capacidade tecnológica e tornarem-se internacionalmente competitivas. Para tal, três tipos de fatores foram analisados: (1) os fatores intrafirma; (2) os fatores interfirmas pelas alianças estratégicas; e (3) os fatores exógenos à firma em cinco empresas do setor eletro-eletrônico brasileiro. Conclui-se que as alianças estratégicas podem acelerar o desenvolvimento da capacidade tecnológica das empresas que já possuem capacidade de absorção para tanto. A influência dos fatores exógenos, tais como as características do mercado e as políticas públicas, são percebidos pelos entrevistados de maneira desigual, impossibilitando uma conclusão específica sobre o impacto no desenvolvimento da capacidade tecnológica e possível associação com os outros dois fatores. Futuras pesquisas deverão ter como objeto o impacto dos fatores exógenos para seu melhor entendimento.

Palavras-chave: alianças estratégicas; capacidade de absorção; capacidade tecnológica; setor eletro-eletrônico.

\begin{abstract}
Intense competition has influenced firms to strength investments in strategic alliances worldwide in order to build up technological capability. In the case of Brazil, pressure to open markets and the internationalization of the competition has led companies to seek alternative forms of accelerating technological development. The aim of this paper is to look into how Brazilian companies manage to increase their technological capabilities by examining the factors that make them internationally competitive. In order to achieve this, three types of factors are analyzed: (1) intra-firm factors; (2) inter-firm strategic alliances; (3) factors that are external to the firm at five companies operating in the Brazilian electronics industry. We conclude that strategic alliances can speed up the technological capability development of firms possessing an initial absorptive capacity. Not all the people interviewed are of the same opinion as to how external factors, such as market characteristics and public policies, influence the development of technological capacity, and it is therefore not possible to reach a definite conclusion concerning a possible association with the other two factors. Future research should take a closer look at external factors in order to understand them better
\end{abstract}

Key words: strategic alliances; absorptive capacity; technological capacity; electro-electronic industry. 


\section{INTRODUÇÃO}

A realidade da economia atual, especificamente aquela relacionada aos países emergentes, como Brasil, Índia, China e Coréia do Sul, e abertos à competição internacional, obriga as empresas a construírem capacidade tecnológica para serem competitivas. Observa-se que a competitividade, com ênfase na capacidade de reduzir os ciclos de produção, de lançamento de novos produtos, e assistência aos clientes, relaciona-se com a intensificação dos serviços.

No caso do Brasil, a pressão da abrupta abertura dos mercados, no início da década de 90, e consequente internacionalização da competição nas empresas é um fator que tem estimulado as empresas a buscarem formas alternativas de fortalecimento da sua capacidade de inovação (Balbinot, 2005). O próprio governo brasileiro tem adotado várias estratégias, que vão desde os programas para promoção das exportações (www.apexbrasil.com.br) até a criação de fundos e legislação para incentivar e fomentar os investimentos em ciência, tecnologia e inovação (www.mct.gov.br; www.bndes.gov.br; www.finep.gov.br), na tentativa de promover um ambiente mais propício ao desenvolvimento da capacidade tecnológica pelas empresas nacionais. Entretanto essas iniciativas não são igualmente efetivas em todos os setores da indústria brasileira.

Para fins deste trabalho, optou-se pela análise do setor eletro-eletrônico, vista a sua importância para o desenvolvimento nacional. Trata-se de setor que interfere na competitividade de praticamente todos os outros setores da economia brasileira. Entre outros, o país vive um aumento significativo da demanda por produtos eletro-eletrônicos, fortemente pressionado pelo crescimento dos setores de telecomunicações e informática, exploração de petróleo, energia elétrica e automotivo (Tavares, 2001).

Em termos de necessidade de expansão desse setor, pode-se mencionar, por exemplo, o aumento no número de computadores no Brasil, em 1995, isso representava 2 milhões e 300 mil, em 2008 já são mais de 40 milhões de computadores operando no país; ou ainda, o número de brasileiros que acessam a Intenet de suas casas que passou de 18,5 milhões de usuários em 2007 para 23,7 milhões de usuários em 2008, segundo os dados do Ibope/NetRatings (Terra, 2008).

A participação do setor eletro-eletrônico no PIB brasileiro foi da ordem de 4,3\% em 2008, mostrando sua importância para a economia nacional. Além disso, ele tem afetado a balança comercial, pois vem apresentando déficits há vários anos. De acordo com os dados da Associação Brasileira da Indústria Elétrica e Eletrônica [Abinee], de janeiro a agosto de 2008, o déficit foi de US\$ 14,94 bilhões (Agência Estado, 2008).

Outro dado importante é a desigualdade do setor eletro-eletrônico no Brasil comparado com outros países: a maioria dos países emergentes é superavitária nesse setor. Tavares (2001) informa que Malásia, Singapura, Coréia, Tailândia, Irlanda, México, Indonésia e Costa Rica estão em melhor posição que o Brasil. Porém cabe salientar que o processo de desenvolvimento da indústria eletrônica brasileira está em plena expansão.

Nesse contexto, o objetivo do presente artigo é examinar a questão de como as empresas brasileiras do setor eletro-eletrônico conseguem desenvolver capacidade tecnológica para tornarem-se internacionalmente competitivas. Para tal, propõe-se a análise de três mecanismos, quais sejam os fatores intrafirma, os fatores interfirmas pelas alianças estratégicas e os fatores exógenos à firma, em cinco empresas do setor eletro-eletrônico brasileiro.

\section{CONTEXTO}

Durante a década de 60 até a década de 80, as iniciativas governamentais focavam no desenvolvimento de setores considerados estratégicos pelo governo militar. Particularmente, na década 
de 80, o grave processo inflacionário pelo qual o país passou influenciou negativamente o planejamento de longo prazo no que diz respeito aos investimentos em $\mathrm{P} \& \mathrm{D}$ e aqueles outros de alto risco. O setor eletro-eletrônico foi bastante afetado especialmente durante o período conhecido como Reserva de Mercado (entre as décadas de 1970-1990). Desde a década de 1990 até 2008, o setor passou por uma fase de reestruturação produtiva e intensificação nos investimentos em P\&D para adquirir e fortalecer sua competitividade em face da concorrência internacional.

Alguns autores apontam a importância do relacionamento entre empresas localizadas nos países

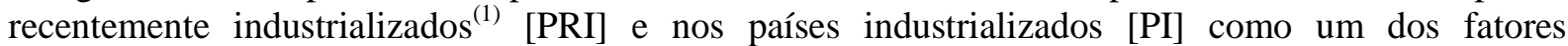
dinamizadores do processo de introdução de novas tecnologias nos PRI (Balbinot, 2005). Cabe informar que uma das diferenças entre esses dois tipos de países refere-se ao processo de difusão tecnológica que possui papel fundamental no processo de inovação (Viotti, 2002). De fato, essa distinção é particularmente relevante, quando se busca entender as diferenças nos quadros analíticos sobre o aumento de capacidade tecnológica que consideram os ambientes onde as empresas desenvolvem essa capacidade. Deve-se mencionar que a capacidade para inovar faz-se necessária em qualquer um desses países, pois tornou-se um dos principais fatores que influenciam a dinâmica do desenvolvimento econômico e social. Contudo a principal diferença encontra-se na forma como isso ocorre, impactando no tipo de política de desenvolvimento tecnológico que deve ser adotado para cada um desses grupos de países.

Os PRI, como o Brasil, apresentam uma distribuição espacial do desenvolvimento industrial desigual. Nesse sentido, existem empresas que são competitivas internacionalmente localizadas em alguns Estados do Brasil, enquanto aquelas localizadas em outras regiões, principalmente no norte, nordeste e centro-oeste, ainda não ultrapassaram as barreiras tecnológicas e não tem competitividade internacional na sua maioria, conforme pesquisa do Instituto de Pesquisa Econômica Aplicada [IPEA] (2008).

Logo, a diferença apresentada por Viotti (2002) é essencial dentro do contexto do presente artigo. Por tratar-se de estudo sobre fatores que influenciam o desenvolvimento da capacidade tecnológica, o intercâmbio de conhecimento com as empresas parceiras de PI torna-se vital para o desenvolvimento tecnológico pelas empresas de PRI. Nesse sentido, as alianças estratégicas passam a ser um mecanismo interfirmas importante no processo de desenvolvimento. Para tanto parte-se do pressuposto de que é pré-requisito para utilizar esse tipo de mecanismo a pré-existência de capacidade tecnológica nas empresas.

Além da importância para o país, anteriormente mencionada, a seleção do setor eletro-eletrônico é também justificada porque ele possui certo nível de capacidade tecnológica, necessário para entrar em uma estratégia de aliança (Balbinot \& Bignetti, 2007). De fato, observando as fases da economia brasileira nos últimos 20 anos, podemos concluir que esse setor desenvolveu considerável capacidade tecnológica durante a Reserva de Mercado.

Nesse período, a indústria eletro-eletrônica brasileira desenvolveu-se com foco no mercado interno brasileiro, sendo a competição com empresas estrangeiras mínima, e com investimentos em desenvolvimento tecnológico interno pela utilização da infraestrutura de ciência e tecnologia [C\&T] disponível. Essa infraestrutura apoiou a construção de capacidade tecnológica nas empresas, considerando que elas desenvolveram capacidade para avaliar, explorar e utilizar o conhecimento externo (Cohen \& Levinthal, 1990; Lall, 1992). Consequentemente, supõe-se que algumas empresas deste setor adquiriram a capacidade necessária para a realização de intercâmbio tecnológico com empresas estrangeiras.

Logo, as empresas brasileiras buscaram desenvolver capacidade tecnológica pelo aproveitamento das condições que o ambiente externo a elas proporcionava e que estava relacionado à Reserva de Mercado e à disponibilidade de infraestrutura de C\&T nas instituições governamentais e privadas. Comparativamente, alguns dos maiores países emergentes asiáticos - China, Coréia do Sul e Índia adotaram o caminho inverso. Eles privilegiaram as transferências de tecnologia estrangeira para desenvolver sua capacidade tecnológica interna (Hauser, Zen, \& Selao, 2007; Kumar, Kumar, \& 
Persaud, 1999; Lall, 1985; Westphal, Kim, \& Dahlman, 1985). Segundo Hauser et al. (2007) o caminho seguido pelos países asiáticos resultou em um melhor desempenho da participação daqueles países no mercado global e em inovações do que o Brasil, se verificados os níveis tecnológicos de ambos.

Recentemente, a economia brasileira vem sofrendo profundo processo de reformas institucionais e econômicas que tiveram seu auge na década de 90 e agora sofrem o seu aprofundamento e reorganização. Depois de três décadas sem política industrial, o atual governo lançou em 2003 a Política Industrial, Tecnológica e de Comércio Exterior [PITCE], a Lei de Inovação em 2004, a Lei do Bem em 2005 e a Lei da Informática revisada. Os investimentos em C\&T têm crescido anualmente desde 2000 e os financiamentos de subvenção à inovação na empresa foram iniciados em 2006 (www.mct.gov.br). O objetivo é ampliar os benefícios do processo de desenvolvimento relacionado à internacionalização e inovação, os quais caracterizam os novos padrões da economia global em expansão até 2007 e que entrou em colapso em 2008 em face da crise financeira americana e européia. Nesse contexto, as empresas buscam eficiência, eficácia e melhoria na competitividade internacional.

\section{CONSTRUINDO CAPACIDADE TECNOLÓGICA: O QuÊ?}

\section{Conceito}

A literatura sobre capacidade tecnológica nos PRI surgiu, a partir da década de 1970, com alguns estudos empíricos sobre a natureza, intensidade e determinantes do desenvolvimento tecnológico nas empresas (Costa \& Queiroz, 2002; Katz, 1976). O argumento utilizado por esses estudos é que as empresas, nesses países, não podem ser consideradas meros usuários de tecnologias importadas, porque elas adaptam essas tecnologias às necessidades e condições locais (Capdevielle, Cimoli, \& Dutrénit, 1997; Katz, 1976, 1998; Katz \& Kosacoff, 1998). O principal foco reside, então, na construção de capacidade tecnológica de níveis básicos de produção, ou rotineiros, para níveis de capacidade inovadora (Dutrénit, 2001; Figueiredo, 2003a, 2003b).

Existe uma variedade de definições para capacidade tecnológica. Estudos anteriores consideravam capacidade tecnológica como aquela relacionada aos esforços sistemáticos para aquisição de conhecimento necessário às melhorias da capacidade produtiva da empresa (Katz, 1976). Outros estudos referem-se à "capacidade de gerenciar a tecnologia e implementar mudanças técnicas" (Bell, 1984, p. 189). Alguns outros ainda consideram o conceito de habilidade dos indivíduos, incluindo a infraestrutura disponível e atividades realizadas, para dar execução a mudanças nas técnicas e na produção em sua definição (Figueiredo, 2003a, referindo-se aos estudos de Bell, 1982). A capacidade tecnológica pode, ainda, referir-se às habilidades e competências da empresa para criar, absorver, adaptar e modificar tecnologias, ou seja, inovar. Kharbanda e Jain (1997) consideram que, no caso das empresas localizadas nos PRI, ela refere-se à capacidade local para absorver, adaptar e modificar tecnologias que são transferidas durante os processos de importação.

Nesse artigo considera-se capacidade tecnológica como um conjunto de habilidades funcionais que impactam o desempenho da empresa e cujo propósito último é administrar a geração de valor. Nesse processo são apreendidas e incorporadas habilidades organizacionais difíceis de serem imitadas, gerando conhecimento tácito específico (Panda \& Ramanathan, 1996). Esse conceito é aplicado aos PRI, cujas empresas são classificadas, com algumas exceções, como de capacidade tecnológica rotineira.

A capacidade tecnológica pode ser dividida em dois níveis: (1) rotineira, considerada como aquela necessária para operar a produção e implementar pequenas melhorias em processo, equipamentos, máquinas, software, produto e gestão; (2) inovadora, refere-se àquelas atividades mais complexas, 
necessárias para gerar, gerenciar e implementar mudanças tecnológicas nos produtos, produção e organização (Lall, 1992).

Outros autores utilizam maior número de níveis de capacidade tecnológica. Bell (1984) e Lall (1992), por exemplo, falam de cinco e seis capacidades respectivamente: (1) aquisitiva; (2) operadora; (3) adaptadora, sendo essas três primeiras consideradas sobretudo como rotineiras e (4) inovadora; (5) treinadora; (6) transferidora, essas últimas enquadrando-se na definição de Lall (1992) como inovadoras.

\section{Diferenças entre os Ambientes PI e PRI}

Em geral, as empresas localizadas em países que têm suas economias nacionais mais estáveis, os ditos PI, vivem em ambiente consolidado para a inovação. Consequentemente, a infraestrutura de $\mathrm{C} \& \mathrm{~T}$, tanto quanto suas relações com empresas e os esforços de P\&D internos, estão estabelecidos. As empresas já têm suas habilidades para inovar e são ativas para aprender pelas atividades de pesquisa que desenvolvem, promovendo avanços em relação à fronteira tecnológica (Bell \& Pavitt, 1993; Kim, 2002), podendo conceber e utilizar políticas para o fortalecimento de Sistemas Nacionais de Inovação (Viotti, 2002).

Por outro lado, como sinalizado por Viotti (2002), os países emergentes, ou PRI, devem focar seus esforços no estabelecimento e desenvolvimento de Sistemas Nacionais de Aprendizagem, onde a difusão apresenta um papel vital no desenvolvimento tecnológico.

A discussão acima torna-se relevante para a investigação sobre o processo de construção de capacidade tecnológica por empresas localizadas nos PRI, porque auxilia no exame dos impactos das alianças estratégicas entre essas empresas e aquelas localizadas nos PI. No entanto existem outros fatores igualmente relevantes que impactam essa construção. A seção a seguir examinará esses fatores.

\section{CONSTRUINDO a CAPACIDAdE TeCNOlÓGICA: FATORES CONDICIONANTES}

A capacidade tecnológica é frequientemente relacionada a diversos fatores condicionantes que podem ser agrupados em três domínios: fatores intrafirma, fatores interfirmas, caso das alianças estratégicas; e fatores exógenos à firma. A natureza e a qualidade com que a empresa realiza atividades relacionadas a esses três domínios pode auxiliar o desenvolvimento de sua capacidade tecnológica em duas direções: no fortalecimento da capacidade já existente e/ou no desenvolvimento da capacidade tecnológica para níveis mais elevados, como, por exemplo, na mudança de capacidade adaptadora para capacidade inovadora (Marques \& Oliveira, 2006).

\section{Fatores Intrafirma}

O aprendizado tecnológico e organizacional como um todo é considerado elemento-chave dentre os fatores condicionantes intrafirma (Bell, 1984; Bell \& Pavitt, 1993; Kim, 1997). Bell define o aprendizado tecnológico como "the acquisition of additional technical skill and knowledge by individuals and through them by organisations" (Bell, 1984, p. 188).

Regra geral, a literatura sobre aprendizado tecnológico considera que os indivíduos são o principal foco do aprendizado nas empresas, que podem estar organizadas de forma a transformar o aprendizado individual em aprendizado organizacional. A base para analisar a estratégia de tal processo de transformação é considerar a gestão de dois tipos de conhecimento: o tácito e o explícito. A dimensão tácita está localizada na mente das pessoas e baseia-se em suas competências e conhecimentos adquiridos ao longo de suas vidas, enquanto a dimensão explícita está disponível em manuais, relatórios e documentos, ou seja em blue prints. 
O conhecimento tácito é o componente fundamental para o completo entendimento dos blue-prints, ou seja, o entendimento do quê, do porquê e como. De fato, o aprendizado tecnológico é atividade cara que envolve diversos mecanismos e motivações, além de ser cumulativo e dependente do conhecimento prévio, ou seja, é dependente da capacidade de absorção da empresa e, conseqüentemente, dos indivíduos que nela trabalham. Há diversos estudos sobre mecanismos de aprendizado pela empresa que podem ser agrupados em três áreas: economia (Arrow, 1962), administração (Simon, 1945) e inovação (Leonard-Barton, 1995).

Pesquisas na área da administração, baseadas na psicologia, tradicionalmente exploram duas dimensões do aprendizado: processos e mecanismos embasando o aprendizado organizacional (Argyris \& Schön, 1978) e a criação de conhecimento por organizações pela conversão de conhecimento tácito em explícito (Nonaka \& Takeuchi, 1996). Particularmente relevante para este artigo é a associação do aprendizado da implantação de mudanças e não só na aquisição de conhecimento, vista a necessidade de construção de capacidade tecnológica.

Existem alguns mecanismos que contribuem para o aprendizado tecnológico. Entre esta miríade de mecanismos, Bell (1984) considera que o aprendizado é usualmente associado a dois tipos de esforços. Primeiro, o aprendizado pelo fazer (learning-by-doing), dizendo respeito à aquisição de competências e conhecimentos técnicos baseados na experiência das pessoas. Segundo, são considerados os mecanismos de aprendizado baseados em outras atividades, tais como recrutamento e treinamento de pessoas e pesquisa, entre outros. Estes mecanismos estão associados aos investimentos e esforços das empresas para "increasing their capacity to manage technology and to implement technical change" (Bell, 1984, p. 189).

O aprendizado baseado no fazer é, portanto, dependente da experiência, sendo passivo, automático e sem custo, enquanto os outros mecanismos dependem de investimentos e esforços ativos para a aquisição de conhecimento tecnológico. Essas formas de aprendizado acontecem paralelamente na empresa e são responsáveis pela composição da chamada capacidade de absorção delas. Assim, a capacidade de absorção está diretamente relacionada com a capacidade tecnológica, podendo ser até confundida com ela. No entanto a capacidade de absorção é o fator interno que condiciona a construção de capacidade tecnológica.

Considera-se a capacidade de absorção como "the ability of a firm to recognize the value of new, external information, assimilate it, and apply it to commercial ends ... it is largely a function of the firm's prior related knowledge" (Cohen \& Levinthal, 1990, p. 128). A capacidade de absorção, dessa forma, pode representar tanto um facilitador como um obstáculo para a mudança no nível da capacidade tecnológica empresarial. A falta de investimentos na mesma dificulta o aprendizado contínuo necessário para a progressão no estágio de capacidade tecnológica. Porém a presença de investimentos constantes e de mecanismos de aprendizagem, que vão além do aprender-fazendo, geram uma atitude proativa no sentido de reduzir as incertezas inerentes ao processo de inovação e reconhecer o valor externo do conhecimento, desenvolvendo recursos humanos, melhorando a qualidade das relações em rede, melhorando a gestão organizacional e as rotinas, e desenvolvendo processos de aprendizado adequados à capacidade tecnológica inovadora (Arnold, Allinson, Muscio, \& Sowden, 2004).

\section{Alianças Estratégicas}

A construção de capacidade tecnológica pelas empresas localizadas nos PRI geralmente é associada à aquisição de tecnologias estrangeiras (Katz \& Kosacoff, 1998; Kim, 1997) via assistência técnica, acordos de licenciamento, serviços de engenharia, serviços técnicos, administração de projetos e supervisão técnica, entre outros mecanismos envolvidos em uma aliança estratégica.

Entende-se que o potencial para a construção de capacidade tecnológica por meio desses mecanismos está relacionado aos esforços de aprendizagem intrafirma, ou seja, sua capacidade de absorção, discutido anteriormente, e por fatores exógenos que serão examinados posteriormente. É 
importante salientar que a aliança estratégica entre empresas não gerará um avanço na capacidade tecnológica delas, ou seja, uma mudança de nível, se elas não possuírem a capacidade de absorção necessária para a realização de tal avanço.

De fato, as alianças estratégicas podem acelerar o processo de desenvolvimento da capacidade tecnológica, porque permitem uma transformação mais rápida do conhecimento tácito em explícito, descrito no modelo SECI de Nonaka e Takeuchi (1996), quando envolvem o contato entre os recursos humanos das empresas parceiras (Inkpen, 1996; Killing, 1980). Neste caso, o tipo de aprendizado observado pode ser considerado como aprendizado-por-interação, pois acontece pelo compartilhamento de conhecimento, contribui para a aquisição de novos conhecimentos e, conseqüentemente, influencia saltos no nível de capacidade tecnológica (Sercovitch, 1988).

Existem tipos diferentes de alianças estratégicas e cada qual está relacionado a elementos característicos distintos. O principal elemento é a transferência de conhecimento tecnológico, que a aliança proporciona, quando existe a sistematização da transferência da tecnologia de um grupo de pessoas localizado em uma empresa para o outro grupo localizado em outra empresa. Sendo assim, o conceito de transferência de tecnologia considerado neste artigo vai além da simples aquisição de equipamentos, pois considera que a empresa recebedora assimila e domina a nova tecnologia.

Como resultado, o modo de transferência de tecnologia envolve uma próxima interação entre ambas as empresas parceiras, permitindo melhor compreensão do conhecimento explícito dos blue prints e contribuindo para a ampliação do conhecimento tácito de ambas as empresas. Teoricamente, alianças estratégicas são o modo mais fácil de transferência de tecnologia, permitindo que os parceiros permaneçam juntos durante o tempo necessário para a adoção, aceitação e assimilação da tecnologia transferida (Gilbert \& Cordey-Hayes, 1996).

Outro elemento considerado nas alianças estratégicas é a dependência entre as empresas parceiras (Killing, 1980). A dependência de uma empresa do seu fornecedor de tecnologia é reduzida, quando a tecnologia a ser transferida está relacionada às áreas de domínio da empresa, considerada a partir da sua própria capacidade tecnológica. Por outro lado, se a tecnologia a ser adquirida é desconhecida da empresa, então será necessária uma relação muito próxima com a empresa fornecedora da tecnologia na aliança estratégica estabelecida e a realização de investimentos na capacidade de absorção. Por exemplo, em um acordo de licenciamento, a empresa compradora deverá ter profundo conhecimento sobre a tecnologia que está adquirindo, uma vez que esse tipo de aliança estratégica pressupõe baixa integração entre as empresas parceiras. Pelo contrário, as joint ventures assumem alto nível de integração, uma vez que elas envolvem, muitas vezes, o desenvolvimento conjunto de tecnologias que ainda não são amplamente conhecidas.

Para fins deste trabalho, define-se aliança como acordo de cooperação realizado entre duas ou mais empresas independentes. A aliança considera o desenvolvimento de um projeto específico, por determinado período de tempo, com metas bem definidas, que envolve o desenvolvimento mútuo de competências (Garrette \& Dussauge, 1995). Assim, a aliança propicia o compartilhamento de um pool de recursos e a coordenação dos esforços para o alcance de resultados que não poderiam ser obtidos, caso as empresas agissem sozinhas.

Como mencionado anteriormente, a capacidade de absorção inicial da empresa é uma condição sine qua non para a entrada na aliança, dada a complexidade das atividades e conhecimentos envolvidos, os quais requerem coordenação e controle para influenciarem o desenvolvimento de capacidade tecnológica pela empresa. Considerando que uma aliança é ferramenta importante para intercâmbio de conhecimento, a empresa que não possuir um nível mínimo de capacidade de absorção, não irá desenvolver o canal de comunicação necessário para o entendimento das informações que estarão sendo transferidas (Leonard-Barton, 1995).

Geralmente, as empresas localizadas nos PRI possuem capacidade de absorção limitada, o que implica a necessidade de uma interação próxima com as empresas fornecedoras de tecnologia localizadas nos PI e investimentos na capacidade de absorção em, por exemplo, acordos do tipo joint 
ventures. De fato, é necessário o desenvolvimento de atividades que requerem médio ou alto grau de integração entre as empresas parceiras (Hamel, 1991). Esse tipo de integração poderá levar a empresa recebedora a realizar investimentos, influenciando-a no desenvolvimento de atividades para a gestão da mudança tecnológica que impactam a sua capacidade tecnológica de forma a elevá-la para patamares inovadores.

O novo conhecimento recebido serve como base para a renovação do conhecimento organizacional, podendo sustentar a vantagem competitiva da empresa no longo prazo (Inkpen, 1996). A acumulação de conhecimento pela empresa gera capacidades que são específicas da empresa. Essas capacidades proporcionam os avanços tecnológicos que são relacionados às adições incrementais de conhecimento ao estoque atual. Esse processo, na realidade, pode ser considerado como o coração do sistema de desenvolvimento tecnológico empresarial.

Para as empresas localizadas nos PRI, o problema chave para o desenvolvimento tecnológico não é somente a obtenção de tecnologia, trata-se igualmente da adaptação e implementação da tecnologia ao contexto da empresa e do mercado, fato esse que depende do quanto a empresa domina a tecnologia transferida. Como resultado, a tecnologia adquirida deverá ser desenvolvida e utilizada para que efetivamente facilite o desenvolvimento industrial local (Chang, Hsu, \& Tsai, 1999). Assim, a simples aquisição não significa necessariamente que a tecnologia está sendo efetivamente utilizada em seu completo potencial.

Logo, os relacionamentos interfirmas podem ser considerados como facilitadores do desenvolvimento de capacidade tecnológica, se, e somente se, houver compatibilidade entre os níveis de capacidade tecnológica das empresas parceiras. Igualmente, conforme mencionado anteriormente, a capacidade inicial de absorção é essencial para que o comprador possa entender e utilizar a tecnologia recebida. Caso essas condições não sejam atendidas, as alianças estratégicas não servirão como veículo para o desenvolvimento da capacidade tecnológica em PRI.

Outro obstáculo importante que deve ser mencionado é a resistência dos indivíduos de ambas as empresas no processo de transferência de tecnologia. Visto que o contato físico e contínuo é essencial para a boa utilização desse mecanismo, uma não-aceitação do grupo em compartilhar conhecimentos pode significar o fim do processo. Sendo assim, um processo de sensibilização dos grupos torna-se necessário para o funcionamento eficiente desses relacionamentos entre empresas.

\section{Fatores Condicionantes Exógenos à Empresa}

Como o desenvolvimento tecnológico é uma das principais forças motoras do desenvolvimento nacional, todos os países desenvolvem e implementam mecanismos para a criação e fortalecimento de ambientes propícios ao processo de construção e fortalecimento da capacidade tecnológica pelas empresas. No caso do Brasil, vários programas nacionais foram estabelecidos. Considerando o período de industrialização do país, políticas protecionistas à indústria nascente foram estabelecidas a partir da década de 1950. Essas políticas consolidaram-se nas décadas de 60 e 70, sendo aliadas às estratégias de construção de infraestrutura de C\&T e transferência tecnológica de empresas estrangeiras para empresas brasileiras.

Quando o Brasil mudou sua estratégia de desenvolvimento industrial, implementando políticas neoliberais e abrindo seu mercado para a competição internacional na década de 1990, ocorreu uma reestruturação industrial fortemente orientada pela idéia de que as empresas brasileiras estariam longe de serem competitivas em face das suas concorrentes nos PI. De fato, a abertura do mercado nacional para as empresas de outros países forçou as empresas brasileiras a adaptarem-se e tornarem-se mais competitivas e inovadoras para sobreviverem no mercado nacional e se internacionalizarem. Os resultados desse processo podem ser observados atualmente: aproximadamente 400 empresas brasileiras possuem lugar de destaque no mercado global, inovando nos produtos e tendo marcas reconhecidas (De Negri \& Salerno, 2005). 
De fato, estudos sobre o desenvolvimento tecnológico de empresas localizadas nos PRI apontam uma série de fatores exógenos condicionantes de tal desenvolvimento. Tais fatores vão de políticas governamentais, instituições e cultura, à infra-estrutura de C\&T e suas relações com a economia, entre outros (Arocena \& Sutz, 1999; Katz, 1998; Kim, 1997).

Regra geral, a literatura sobre os fatores exógenos à empresa, que condicionam sua capacitação tecnológica, explora o desempenho inovador de países e regiões e os relaciona a três grupos de fatores: (1) relações entre empresas e outras organizações que contribuem para o processo de inovação, especialmente universidades e centros tecnológicos; (2) características da infraestrutura em C\&T; e (3) políticas públicas (Cassiolato \& Lastres, 1999; Dahlman \& Frischtak, 1990; Kim, 1997; Viotti, 2002). A interação das relações desses grupos e seus fatores condicionantes influencia os processos de aprendizado tecnológico e as consequentes mudanças na base de conhecimento, levando ao fortalecimento e construção da capacidade tecnológica e de absorção pelas empresas (Cooke, Uranga, \& Etxebarria, 1997; Freeman, 1987; Nelson \& Rosenberg, 1993).

A literatura sobre sistemas de inovação nos PRIs segue as metodologias desenvolvidas para examinar sistemas nacionais nos PI e não considera o recorte setorial ou tecnológico, critica Viotti (2002). Seguindo as metodologias para a análise do ambiente para a inovação em PI, a literatura sobre os PRI conclui que as firmas nesses países têm capacidade tecnológica limitada e pouca conexão com instituições de C\&T (Albuquerque, 1996; Katz, 2000; Viotti, 2002). Além disto, as conexões com instituições de C\&T, tais como universidades e centros tecnológicos, seriam, na maioria dos casos, aquelas necessárias à substituição de seus esforços internos para inovação e não aquelas complementares a tais esforços (Velho \& Saenz, 2002). De fato, instituições de C\&T geralmente realizam pesquisas autossustentáveis para seu desenvolvimento, sendo pequeno o número de casos em que há uma transferência bem-sucedida de resultados para o setor industrial.

Outros pesquisadores concluem que o governo federal tem fomentado pouco o desenvolvimento da capacidade tecnológica pelas empresas locais e, estas, em consequência, não têm as capacidades necessárias para competir em mercados globais. Da mesma forma, a maior parte delas não acumulou capacidade tecnológica inovadora que possibilite a contratação de pesquisas em universidades ou centros tecnológicos e a efetiva transferência de tecnologia possibilitada pelas alianças estratégicas (Bernardes, 2000; Katz, 2000, 2001).

Por outro lado, existe o argumento de que políticas públicas tiveram papel importante no processo de desenvolvimento tecnológico dos países latino-americanos. Pesquisadores como Katz e Capdevielle argumentam que a industrialização durante o período de substituição das importações (entre 1940 e 1980) promoveu a acumulação de capacidade tecnológica nas empresas locais, o que ocorreu principalmente entre as décadas de 1970 e 1980, bem como a construção de uma base de conhecimento sobre a qual as empresas mudaram seus níveis de capacidade tecnológica (Capdevielle et al., 1997; Katz, 1998; Katz \& Kosacoff, 1998). Este processo de desenvolvimento tecnológico pode ser observado essencialmente nas multinacionais instaladas na região e nas empresas estatais.

No entanto, a partir dos anos 90, as políticas de liberalização associadas à privatização e à desregulamentação dos mercados resultaram numa desconexão institucional entre empresas, instituições locais de C\&T e políticas governamentais. Tal desconexão influenciou e influencia negativamente a capacidade tecnológica pelas pequenas e médias empresas brasileiras fornecedoras da Embraer, por exemplo (Bernardes, 2000).

Finalmente, pergunta-se sobre o impacto das políticas governamentais brasileiras na construção de capacidade tecnológica por empresas do setor eletro-eletrônico brasileiro, considerado como significativamente distante da fronteira tecnológica global (Knight \& Marques, 2008). Aparentemente, não existe uma empresa brasileira com marca global e ocupando os primeiros lugares na competição global. No entanto esse setor possui uma legislação própria para o incentivo ao seu desenvolvimento no Brasil, além de ser objeto de programas governamentais específicos (ver www.mct.gov.br, tecnologia da informação e comunicação). 


\section{MÉTODO}

Tendo como referência Yin (1994) e Miles e Huberman (1994), o método da pesquisa escolhido foi o qualitativo, considerando múltiplos estudos de caso e a comparação entre os casos. Para tanto entrevistas semiestruturadas, visitas e análise de documentos de cinco empresas do setor eletroeletrônico brasileiro foram realizadas. As empresas foram selecionadas intencionalmente, sendo consideradas aquelas que tinham ou tiveram aliança estratégica com empresas estrangeiras. Os critérios para a seleção das empresas foram: (1) intencionalidade; (2) não probabilístico; (3) acessibilidade às empresas; e (4) empresas pertencentes ao setor elétricoeletrônico.

Especificamente, foram realizadas entrevistas com as pessoas diretamente envolvidas nas alianças estratégicas dessas cinco empresas do setor e coleta de relatórios e outros documentos relacionados ao tema. A história da empresa foi também levada em consideração pela análise dos resultados das entrevistas e dos documentos. Tabela 1 apresenta as informações sobre as cinco empresas analisadas e os entrevistados.

Tabela 1: Descrição das Empresas Analisadas e dos Entrevistados

\begin{tabular}{|c|c|c|c|c|c|}
\hline & Inepar & Aeroeletrônica & Info & Stemac & Polonia \\
\hline $\begin{array}{l}\text { No. de } \\
\text { empregados }\end{array}$ & 6000 & 300 & 400 & 1000 & 12 \\
\hline Região & Sul & Sul & Sul & Sul & Sul \\
\hline $\begin{array}{l}\text { Segmento } \\
\text { setor }\end{array}$ & $\begin{array}{l}\text { Telecomunicações } \\
\text { (aliança estudada) e } \\
\text { Geração de energia e }\end{array}$ & $\begin{array}{l}\text { Componentes } \\
\text { eletro-eletrônicos }\end{array}$ & Hardware & $\begin{array}{l}\text { Geração de } \\
\text { energia }\end{array}$ & $\begin{array}{l}\text { Componentes } \\
\text { eletro- } \\
\text { eletrônicos } \\
\end{array}$ \\
\hline Entrevistados & $\begin{array}{l}\text { Diretor-geral } \\
\text { Diretor JV } \\
1 \text { engenheiro JV } \\
1 \text { engenheiro Inepar }\end{array}$ & $\begin{array}{l}\text { Presidente } \\
\text { Diretor-comercial } \\
2 \text { engenheiros }\end{array}$ & $\begin{array}{l}\text { Presidente } \\
\text { Vice- } \\
\text { presidente } \\
2 \\
\text { engenheiros } \\
\text { brasileiros } \\
1 \\
\text { engenheiro } \\
\text { parceiro }\end{array}$ & $\begin{array}{l}\text { Presidente } \\
2 \\
\text { engenheiros }\end{array}$ & $\begin{array}{l}\begin{array}{l}\text { Diretor- } \\
\text { administrativo }\end{array} \\
\text { Diretor-técnico } \\
2 \text { engenheiros }\end{array}$ \\
\hline
\end{tabular}

O desenho da pesquisa em casos múltiplos foi escolhido em função da complexidade da pesquisa que trata, particularmente, da relação entre alianças estratégicas e capacidade tecnológica, além da identificação de outros dois tipos de fatores que influenciam o desenvolvimento da capacidade tecnológica: fatores intrafirma e exógenos.

\section{Modelo de Análise}

O modelo analítico levou em consideração as seguintes variáveis: (1) capacidade tecnológica e a existência de capacidade de absorção; (2) aliança estratégica e sua motivação, operacionalização e resultados obtidos; e (3) fatores exógenos. Deve-se mencionar que o desenvolvimento da capacidade tecnológica é considerado como consequência dos esforços internos de aprendizagem da empresa e da capacidade de absorção.

Os fatores exógenos que influenciam o desenvolvimento da capacidade tecnológica, considerados como aqueles relacionados às características do mercado e da política governamental, foram identificados durante as entrevistas. Os entrevistados mencionaram, principalmente, a experiência da empresa durante o período da Reserva de Mercado. 
Portanto, o modelo analítico para a identificação das características das cinco empresas, no que se refere à influência da aliança estratégica no desenvolvimento da capacidade tecnológica, está resumido na Figura 1 abaixo.

Figura 1: Modelo Analítico

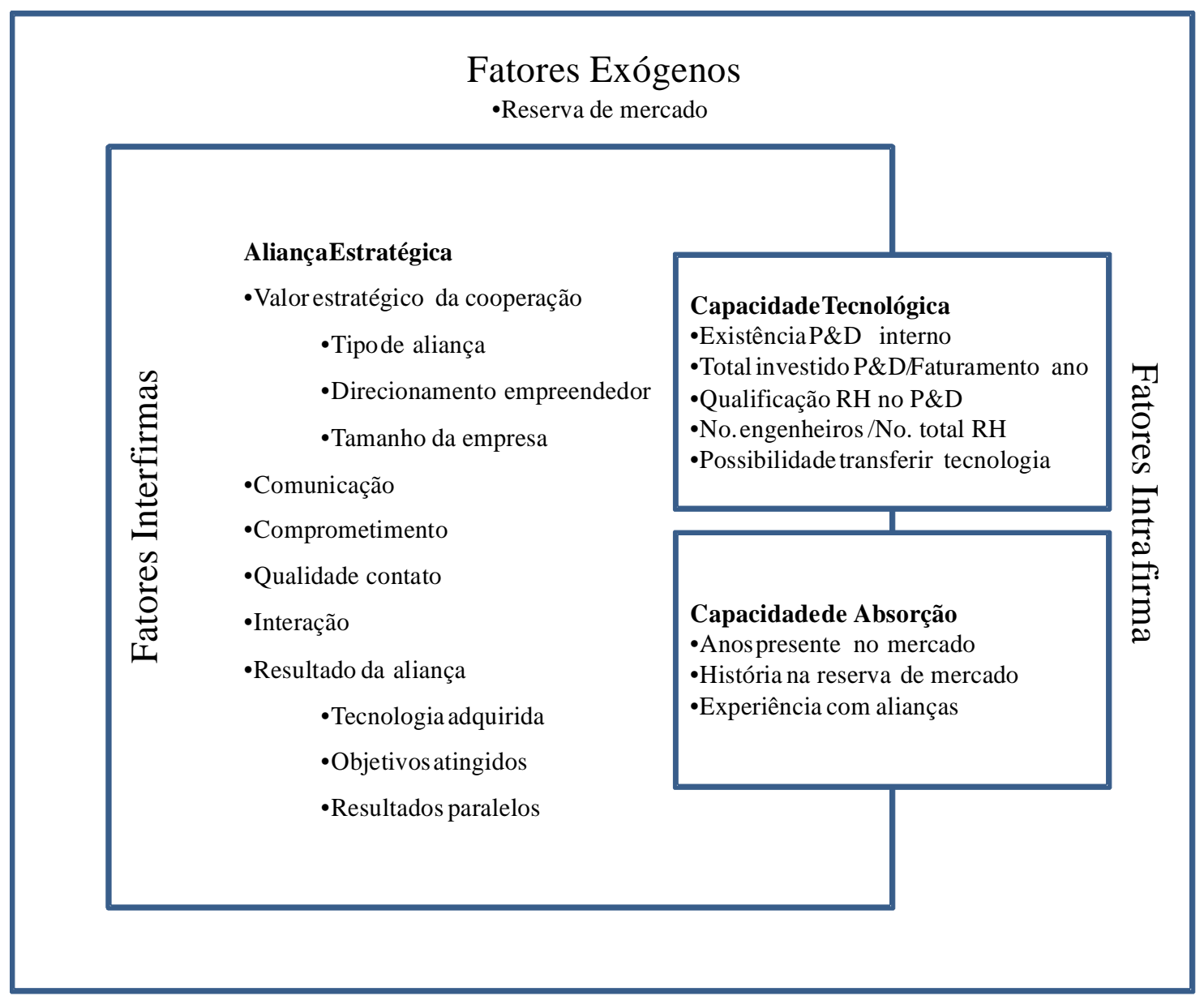

Fonte: adaptado de Balbinot (2005, p. 101).

\section{O SETOR ELETRO-ELETRÔNICO}

O governo brasileiro tem desenvolvido políticas específicas para o setor eletro-eletrônico, porque considera que este é setor chave para que o país consolide a economia e o bem-estar social no longo prazo. Entre outras diretrizes destas políticas, pode-se mencionar o aproveitamento da velocidade das mudanças tecnológicas e as profundas transformações do mercado e da indústria, a construção sobre os pontos fortes existentes no setor, a redução das vulnerabilidades do complexo, assim como ações governamentais decisivas e de longo prazo, de acordo com o Ministério do Desenvolvimento, Indústria e Comércio Exterior [MDIC] (2007).

O eletroeletrônico é setor transversal que tem forte impacto no desenvolvimento da competitividade em todos os outros setores da economia. Atualmente, ele é considerado um dos responsáveis pela difusão das inovações, pelos ganhos de produtividade, redução de custos e estabelecimento dos preços finais dos produtos e serviços (MDIC, 2007). 
As interações de compradores e fornecedores de tecnologia são consideradas estratégicas para o desenvolvimento do setor, particularmente para o desenvolvimento tecnológico dos fornecedores de máquinas, processos e software orientados para as necessidades dos clientes.

Nessas interações, o contato entre as pessoas torna-se imprescindível para a transformação do conhecimento tácito em explícito. As alianças estratégicas observadas envolveram, frequentemente, altos níveis de interação do fornecedor com o comprador da tecnologia. Elas são frequentes no setor.

O faturamento do setor eletroeletrônico representa 4,5\% do PIB do Brasil. Em 2007, a previsão de faturamento indica um crescimento de $12 \%$ em relação a 2006, atingindo o patamar de R\$116,9 bilhões. Apesar do déficit que se acumula há alguns anos, o nível de emprego do setor apresentou crescimento considerável no final do $1^{\circ}$ trimestre de 2007, totalizando 146,4 mil funcionários, apontando o maior nível dos últimos dez anos, segundo dados da Associação Brasileira da Indústria Elétrica e Eletrônica [ABINEE] (2007).

De acordo com o Ministério do Desenvolvimento, Indústria e Comércio Exterior, a formação de alianças globais é ainda pouco expressiva. A indústria eletroeletrônica brasileira é formada, na maior parte, por empresas nacionais, sem vínculos muito fortes com empresas internacionais. Consequentemente, o Brasil não possui posição de destaque no cenário mundial e, ainda segundo o Ministério, terá dificuldades para desenvolver suas exportações (MDIC, 2007). Cabe salientar que a maioria das empresas brasileiras nesse setor são de pequeno porte, podendo ser encontradas até empresas virtuais. Sendo assim, o nível de complexidade organizacional é reduzido, quando comparado com empresas de médio e grande porte e com número maior de empregados.

Alguns dos principais problemas do setor que necessitam ser observados são (MDIC, 2007): (1) grande velocidade de inovações, representando curto ciclo de vida dos produtos (dois anos até poucos meses), relacionado ao longo tempo para que os governos tomem decisões; (2) o tipo de imposto sobre importação que privilegia a compra de produtos acabados no exterior, inibindo a produção local; (3) a relação limitada entre as empresas nacionais e as estrangeiras, impedindo o acesso a novas tecnologias; e (4) as limitações legais com a existência de protecionismos por parte do governo.

Levando-se os aspectos acima em consideração, as cinco empresas são examinadas quanto aos fatores que condicionaram a construção da sua capacidade tecnológica.

\section{ANÁLISE DOS ESTUdOS DE CASO}

Os resultados da pesquisa realizada nas cinco empresas do setor eletroeletrônico, mostrados na Tabela 2 e 3, estão analisadas nas próximas seções. Cabe informar que as respostas foram generalizadas, porque as empresas pediram confidencialidade. 
Tabela 2: Resultados das Alianças Estratégicas dos Cinco Estudos de Caso

\begin{tabular}{|c|c|c|c|c|c|}
\hline $\begin{array}{l}\text { Aliança } \\
\text { Estratégica }\end{array}$ & Inepar & Aeroeletrônica & Info & Stemac & Polonia \\
\hline \multicolumn{6}{|c|}{$\begin{array}{l}\text { Valor estratégico } \\
\end{array}$} \\
\hline Tipo & JV 50-50 & Aliança no equity & Aliança no equity & Licença & JV 20-80 \\
\hline $\begin{array}{l}\text { Direcionamento } \\
\text { empreendedor }\end{array}$ & $\begin{array}{l}\text { A empresa queria } \\
\text { entrar no mercado } \\
\text { de } \\
\text { telecomunicações: } \\
\text { oportunidade }\end{array}$ & $\begin{array}{l}\text { A motivação era } \\
\text { estar preparada } \\
\text { para fornecer para } \\
\text { a Embraer, pela } \\
\text { participação em } \\
\text { programa do } \\
\text { Ministério da } \\
\text { Defesa via } \\
\text { política de } \text { offset }\end{array}$ & $\begin{array}{l}\text { Antecipar o } \\
\text { desenvolvimento } \\
\text { de determinadas } \\
\text { tecnologias }\end{array}$ & $\begin{array}{l}\text { Fornecer para } \\
\text { diferentes } \\
\text { clientes: } \\
\text { oportunidade }\end{array}$ & $\begin{array}{l}\text { Investimento } \\
\text { para o } \\
\text { desenvolvimento } \\
\text { da empresa: } \\
\text { oportunidade }\end{array}$ \\
\hline $\begin{array}{c}\text { Tamanho empresa } \\
\text { RH }\end{array}$ & 6000 & 300 & 400 & 1000 & 12 \\
\hline $\begin{array}{l}\text { Comunicação- } \\
\text { compatibilidade }\end{array}$ & Elevada & Baixa & Média & Baixa & Elevada \\
\hline Comprometimento & $\begin{array}{l}\text { Grande confiança } \\
\text { na aliança e } \\
\text { motivação dos } \\
\text { funcionários } \\
\text { envolvidos }\end{array}$ & $\begin{array}{l}\text { Média motivação } \\
\text { dos funcionários } \\
\text { e baixa confiança } \\
\text { na aliança }\end{array}$ & $\begin{array}{l}\text { Grande confiança } \\
\text { na aliança e } \\
\text { motivação dos } \\
\text { funcionários } \\
\text { envolvidos }\end{array}$ & $\begin{array}{l}\text { Média } \\
\text { motivação dos } \\
\text { funcionários e } \\
\text { grande confiança } \\
\text { na aliança }\end{array}$ & $\begin{array}{l}\text { Pouca motivação } \\
\text { dos funcionários } \\
\text { e quase nenhuma } \\
\text { confiança na } \\
\text { aliança }\end{array}$ \\
\hline Qualidade contato & $\begin{array}{l}\text { Muito boa } \\
\text { socialização das } \\
\text { informações entre } \\
\text { os funcionários e } \\
\text { troca de } \\
\text { conhecimento, } \\
\text { soluções de } \\
\text { problemas em } \\
\text { conjunto }\end{array}$ & $\begin{array}{l}\text { Não houve troca } \\
\text { significativa de } \\
\text { informações entre } \\
\text { os funcionários } \\
\text { para a solução de } \\
\text { problemas em } \\
\text { conjunto }\end{array}$ & $\begin{array}{l}\text { Muito boa } \\
\text { socialização das } \\
\text { informações entre } \\
\text { os funcionários e } \\
\text { troca de } \\
\text { conhecimento, } \\
\text { soluções de } \\
\text { problemas em } \\
\text { conjunto }\end{array}$ & $\begin{array}{l}\text { Muito boa } \\
\text { socialização das } \\
\text { informações } \\
\text { entre os } \\
\text { funcionários e } \\
\text { troca de } \\
\text { conhecimento, } \\
\text { soluções de } \\
\text { problemas em } \\
\text { conjunto }\end{array}$ & $\begin{array}{l}\text { Não houve troca } \\
\text { significativa de } \\
\text { informações } \\
\text { entre os } \\
\text { funcionários } \\
\text { para a solução de } \\
\text { problemas em } \\
\text { conjunto }\end{array}$ \\
\hline Interação & Elevada & Baixa & Elevada & Elevada & Baixa \\
\hline \multicolumn{6}{|c|}{ Resultado } \\
\hline $\begin{array}{l}\text { Tecnologia } \\
\text { adquirida }\end{array}$ & $\begin{array}{l}85 \% \text { da tecnologia } \\
\text { foi } \\
\text { nacionalizada; } \\
\text { conhecimento } \\
\text { sobre tecnologia } \\
\text { de geração de } \\
\text { energia para o } \\
\text { setor de telecom }\end{array}$ & $\begin{array}{l}\text { Produtos foram } \\
\text { totalmente } \\
\text { nacionalizados }\end{array}$ & $\begin{array}{l}\text { Produto foi } \\
\text { totalmente } \\
\text { nacionalizados }\end{array}$ & $\begin{array}{l}\text { Conhecimento } \\
\text { sobre a } \\
\text { tecnologia que a } \\
\text { empresa queria }\end{array}$ & $\begin{array}{l}\text { Várias } \\
\text { tecnologias } \\
\text { foram totalmente } \\
\text { nacionalizadas }\end{array}$ \\
\hline Objetivos atingidos & $\begin{array}{l}\text { Quase. A joint } \\
\text { venture foi } \\
\text { encerrada antes do } \\
\text { prazo }\end{array}$ & $\begin{array}{l}\text { Sim. A aliança foi } \\
\text { o motivo da } \\
\text { melhoria } \\
\text { financeira e } \\
\text { tecnológica da } \\
\text { empresa } \\
\text { brasileira }\end{array}$ & $\begin{array}{l}\text { Sim. Influenciou } \\
\text { um aumento de } \\
142 \% \text { no } \\
\text { faturamento da } \\
\text { empresa } \\
\text { brasileira }\end{array}$ & $\begin{array}{l}\text { Sim. No entanto, } \\
\text { não influenciou } \\
\text { muito na } \\
\text { situação e no } \\
\text { faturamento da } \\
\text { empresa } \\
\text { brasileira. } \\
\text { Faturamento } \\
\text { aumentou apenas } \\
1 \% \text {. }\end{array}$ & Não \\
\hline $\begin{array}{l}\text { Resultados } \\
\text { paralelos }\end{array}$ & & $\begin{array}{l}\text { Outras } \\
\text { tecnologias e } \\
\text { procedimentos } \\
\text { foram } \\
\text { incorporadas pela } \\
\text { empresa } \\
\text { brasileira com } \\
\text { impacto nas } \\
\text { competências } \\
\text { organizacionais }\end{array}$ & $\begin{array}{l}\text { Tiveram acesso a } \\
\text { conhecimentos } \\
\text { específicos sobre } \\
\text { a tecnologia que } \\
\text { queriam } \\
\text { desenvolver }\end{array}$ & $\begin{array}{l}\text { Tiveram acesso } \\
\text { a outros } \\
\text { conhecimentos } \\
\text { sobre outras } \\
\text { tecnologias que } \\
\text { tinham interesse } \\
\text { diferente da } \\
\text { tecnologia } \\
\text { motivo da } \\
\text { aliança }\end{array}$ & $\begin{array}{l}\text { Empresa } \\
\text { brasileira } \\
\text { antecipou o } \\
\text { desenvolvimento } \\
\text { de tecnologias }\end{array}$ \\
\hline
\end{tabular}


Tabela 3: Resultados das Capacidades Tecnológicas e de Absorção dos Cinco Estudos de Caso

\begin{tabular}{|c|c|c|c|c|c|}
\hline & Inepar & Aeroeletrônica & Info & Stemac & Polonia \\
\hline \multicolumn{6}{|c|}{ Capacidade Tecnológica } \\
\hline Existência de P\&D & $\begin{array}{l}\text { Sim: com foco no } \\
\text { desenvolvimento } \\
\text { do produto } \\
\text { especifico para a } \\
\text { joint venture }\end{array}$ & $\begin{array}{l}\text { Sim: com foco em } \\
\text { desenvolvimento } \\
\text { dos produtos da } \\
\text { empresa e não } \\
\text { somente no } \\
\text { produto } \\
\text { relacionado à } \\
\text { aliança estratégica }\end{array}$ & $\begin{array}{l}\text { Sim: possui } \\
\text { laboratório } \\
\text { específico } \\
\text { para P\&D de } \\
\text { novos } \\
\text { produtos }\end{array}$ & $\begin{array}{l}\text { Sim: a maior parte } \\
\text { da atividade de } \\
\text { desenvolvimento } \\
\text { tem foco nas } \\
\text { aplicações dos } \\
\text { produtos }\end{array}$ & $\begin{array}{l}\text { Sim: possui } \\
\text { laboratório } \\
\text { que realiza } \\
\text { P\&D de } \\
\text { produto }\end{array}$ \\
\hline $\begin{array}{l}\text { Total } \\
\text { investido/faturamento } \\
\text { ano }\end{array}$ & $5 \%$ & $7 \%$ & $8 \%$ & $3 \%$ & $10 \%$ \\
\hline Qualificaçao RH P\&D & $\begin{array}{l}\text { Engenheiros e } \\
\text { técnicos em } \\
\text { eletrônica }\end{array}$ & $\begin{array}{l}\text { Engenheiros } \\
\text { mecânico, } \\
\text { eletrônico e } \\
\text { software e } \\
\text { técnicos em } \\
\text { eletrônica }\end{array}$ & $\begin{array}{l}\text { Engenheiros } \\
\text { e técnicos em } \\
\text { eletrônica }\end{array}$ & $\begin{array}{l}\text { Engenheiros } \\
\text { eletrônico, } \\
\text { mecânico e } \\
\text { software e } \\
\text { técnicos em } \\
\text { mecânica e } \\
\text { eletrônica }\end{array}$ & $\begin{array}{l}\text { Físicos, } \\
\text { Engenheiros } \\
\text { eletrônicos } \\
\text { e técnicos } \\
\text { em } \\
\text { eletrônica }\end{array}$ \\
\hline Engenheiros/Total RH & $34 \%$ & $30 \%$ & $25 \%$ & $10 \%$ & $55 \%$ \\
\hline $\begin{array}{l}\text { Transferência } \\
\text { tecnologia }\end{array}$ & Não & Não & $\begin{array}{c}\text { Sim para } \\
\text { fornecedor }\end{array}$ & Não & $\begin{array}{c}\text { Sim para } \\
\text { subsidiárias }\end{array}$ \\
\hline \multicolumn{6}{|c|}{ Capacidade de Absorção } \\
\hline $\begin{array}{l}\text { História empresa - ano } \\
\text { fundação }\end{array}$ & 1953 & 1967 & 1966 & 1951 & 1991 \\
\hline $\begin{array}{l}\text { História reserva de } \\
\text { mercado }\end{array}$ & Sim & Sim & Sim & Sim & Não \\
\hline $\begin{array}{l}\text { Experiência com } \\
\text { alianças }\end{array}$ & Sim & Não & Sim & Sim & Não \\
\hline
\end{tabular}

\section{Fator Intra-firma: a Capacidade Tecnológica}

Como foi dito anteriormente, a capacidade de absorção favorece a empresa no reconhecimento, na descoberta e no entendimento das novas tecnologias que ela precisa implementar para continuar sendo competitiva (Balbinot \& Bignetti, 2007; Cohen \& Levinthal, 1990). De fato, a empresa poderá descodificar a tecnologia, entendendo e modificando o seu conteúdo, conforme a sua capacidade de absorção. Duas das empresas pesquisadas, Inepar e Stemac, reconhecem a importância da informação e das oportunidades para as suas empresas. A habilidade deste reconhecimento e da utilização do conhecimento da informação no desenvolvimento da empresa é um dos fatores considerados por Cohen e Levinthal (1990) como estratégico para a capacidade de inovação. De fato, estas duas empresas identificam o valor e, algumas vezes, até convencem as suas parceiras na aliança sobre os benefícios mútuos da aplicação da informação para o desenvolvimento da tecnologia objeto da aliança.

A Aeroeletrônica e a Info possuem importante potencial para aprendizagem. Ambas estão preparadas para transferir a tecnologia transformada pelas alianças estabelecidas, desenvolvidas pelos seus departamentos de P\&D. Essas empresas têm também privilegiado as alianças nas suas estratégias de desenvolvimento tecnológico. Elas têm a capacidade de absorção necessária para reconhecer a importância de novas informações, aplicando-as para alcançarem as suas metas. Na realidade, elas fazem parte dos segmentos de componentes eletrônicos e hardware respectivamente (veja Tabela 1 do Método), os quais demandam novas tecnologias, o que as obriga a estarem constantemente desenvolvendo as tecnologias utilizadas. Segundo Lall (1992), as empresas que possuem departamento de P\&D e transferem tecnologia possuem capacidade para a inovação em estágio mais avançado, comparado com aquelas que não possuem.

A quinta empresa, chamada de Polônia para fins deste artigo, encontra-se em estágio de investimento na construção da habilidade para reconhecer o potencial das informações para a melhoria 
da empresa. Ela está, portanto, melhorando suas condições internas para aprender, melhorar e transferir tecnologia, ou seja, no processo de construção de capacidade tecnológica para a inovação.

\section{Alianças Estratégicas}

Antes de prosseguir, devemos fazer duas considerações. Primeiro, os resultados paralelos são benefícios advindos das alianças que, contudo, não faziam parte dos objetivos pretendidos. Eles ocorreram como consequência direta da interação propiciada pela aliança (Gilbert \& Cordey-Hayes, 1996; Inkpen, 1996). Segundo, ainda existiam algumas alianças em andamento por ocasião das entrevistas. Consequentemente, os resultados apresentados neste artigo ainda não podem ser considerados como finais. Mesmo assim, eles possibilitam conclusões interessantes para pesquisas futuras.

Quanto aos resultados atingidos pela aliança joint venture entre Lucent e Inepar, ela terminou de forma precipitada. Na realidade, a aliança teve resultados considerados de sucesso para as empresas parceiras e, por isso, a joint venture deveria ter durado mais tempo (Garrette \& Dussauge, 1995). A empresa resultante da joint venture tinha diversos contratos com clientes importantes como a Global Village Telecom [GVT] e a Telefónica, duas das maiores empresas de telecomunicações do Brasil. Igualmente, a joint venture tinha registrado um lucro de US\$ 15 milhões de dólares para o primeiro ano de funcionamento, prevendo para o segundo ano uma receita na ordem de US\$ 30 milhões de dólares. Mesmo com uma duração pequena, a Inepar conseguiu nacionalizar $85 \%$ da tecnologia da Lucent.

A aliança estabelecida pela Aeroeletrônica com a Sundstrand durou até o final do projeto, conforme previsto em contrato. Nesse caso, os empregados da Aeroeletrônica envolvidos ganharam mais do que o conhecimento sobre a tecnologia, desenvolvendo ainda uma estrutura mais eficiente para produzir produtos de alta complexidade tecnológica. Após a melhoria na estrutura e no desenvolvimento da capacidade tecnológica, passando de uma capacidade tecnológica rotineira operadora para uma capacidade inovadora adaptadora e mais tarde treinadora (Bell, 1984; Lall, 1982). Com a aliança, a empresa investiu na implantação de departamento de $\mathrm{P} \& \mathrm{D}$, obtendo sucesso na qualificação para o fornecimento ao setor espacial pelo Instituto Espacial de Pesquisa Espacial [INPE]. Como consequência, a Aeroeletrônica forneceu componentes para 10 satélites no âmbito do programa BrasilChina e, na sequência, forneceu para o primeiro satélite totalmente brasileiro produzido pelo INPE.

No caso da empresa Info, mais do que um dramático aumento nos lucros, a empresa obteve sucesso no desenvolvimento de uma marca de prestígio no mercado internacional. Tratou-se de importante resultado paralelo propiciado pela aliança com o parceiro estrangeiro. Desde a época da aliança, a empresa tem sido contatada por várias empresas estrangeiras interessadas em fazer negócios com ela. Igualmente, a Info aprendeu muito mais do que esperava. Trata-se de exemplo interessante, visto que a empresa aprendeu o que acontecia na empresa parceira por meio da observação. Entre outros, a empresa obteve soluções práticas que aceleraram em um ano a produção de determinados projetos.

Observou-se que o pessoal envolvido na aliança da empresa Stemac absorveu o conhecimento sobre a tecnologia, entre outros, considerados como aqueles de que a empresa necessitava. De fato, o conhecimento adquirido pelo intercâmbio ocorrido durante a aliança ajudou na melhoria dos produtos oferecidos pela empresa.

Finalmente, a empresa Polônia concluiu que o objetivo pretendido não foi alcançado com a aliança. $\mathrm{Na}$ realidade, a empresa pretendia, por meio da aliança, aumentar o seu capital líquido para o desenvolvimento tecnológico. De acordo com os seus diretores, o Grupo Polônia não investiu o dinheiro proposto no acordo. Porém, de um ponto de vista externo, essa aliança não pode ser considerada como caso de total fracasso, visto que Polônia aumentou seus lucros, antecipando o desenvolvimento tecnológico de vários novos produtos. 


\section{Fatores Exógenos às Cinco Empresas Analisadas}

Um dos fatores exógenos às empresas, importante para o caso do setor eletro-eletrônico, foi a Reserva de Mercado. Esse período afetou de forma crucial, positiva ou negativamente, as empresas analisadas. Para a empresa Inepar, por exemplo, de acordo com o seu CEO, esse período foi importante para a realização de negociações, auxiliando-os a entrarem em parceria mais vantajosa com empresas de PI. Utilizando suas palavras: "se você não tivesse a reserva de mercado, qual argumento você usaria para atrair os técnicos para cá?"

No caso das empresas Aeroeletrônica e Info, conclui-se que elas tiveram trajetórias semelhantes. No período da Reserva de Mercado, as duas empresas foram as que tiraram as maiores vantagens, comparadas com as demais empresas entrevistadas. Elas foram parte de um grupo privilegiado de segmentos no qual o governo brasileiro decidiu investir.

De fato, a própria existência da Aeroeletrônica é o resultado de um programa governamental. $\mathrm{O}$ CEO dessa empresa considera que o período da reserva de mercado não foi tão vital para outros setores quanto o foi para o setor aeroespacial, para o qual a Aeroeletrônica fornecia componentes. Essa afirmativa pode ser discutida, mas o que não pode ser discutido é que foi durante esse período que o governo brasileiro controlou, de forma significativa, o desenvolvimento industrial nacional e, de posse de condições estáveis, estabeleceu um plano de desenvolvimento de longo prazo.

No caso da empresa Info, o vice-presidente confirmou a importância da época da Reserva de Mercado para o setor de telecomunicações e para sua própria empresa. Segundo ele, a Info "foi privilegiada com a Reserva de Mercado" pelas vantagens obtidas com as barreiras tarifárias impostas às empresas estrangeiras.

Contudo a principal vantagem que a empresa obteve não foi em termos tarifários. Tratou-se de vantagem comparativa importante por mediação do padrão Telebrás ${ }^{(2)}$. Esse padrão foi a principal barreira para as empresas estrangeiras entrarem no mercado, porque elas tinham de adaptar as suas tecnologias aos critérios e padrões brasileiros definidos pela Telebrás. Como o Brasil não tinha fornecedores estrangeiros trabalhando com o padrão requerido, a responsabilidade foi transferida para as empresas brasileiras, que trabalhavam nos desenvolvimentos tecnológicos necessários à adaptação das tecnologias das empresas estrangeiras, parceiras nas alianças estratégicas. Consequentemente, a Info conseguiu melhorar sua capacidade de absorção, investindo ao mesmo tempo no desenvolvimento da sua capacidade tecnológica.

Quanto à empresa Stemac, o seu presidente tinha uma opinião diferente do valor do período da Reserva de Mercado. Ele considerou esse período difícil para o desenvolvimento tecnológico da empresa. Ele o chamou de período negro, porque, apesar de a empresa ter sido bem sucedida no desenvolvimento interno de tecnologias, durante esse período foi difícil importar produtos estrangeiros e know-how. A Stemac não fez parte de um segmento do setor eletroeletrônico privilegiado pelo governo brasileiro. Consequentemente, ela não se beneficiou do mercado fechado, da mesma forma que as empresas Inepar, Aeroeletrônica e Info.

Finalmente, a empresa Polônia não havia sido fundada nesse período. Entretanto o seu fundador tinha algumas palavras a dizer sobre o período de mercado protegido. Durante essa época, ele trabalhava com material importado e, como resultado da política do momento, ele tinha que pagar altos impostos sobre a importação, o que representou várias dificuldades competitivas no mercado interno. Logo, para ele, a Reserva de Mercado não foi um período considerado positivo. 


\section{O Impacto da Aliança na CAPACIDAde TeCnOlógica: Considerações Finais}

Mundialmente, as empresas estão sendo obrigadas a construírem capacidade tecnológica para fazer face à nova onda de intensa competição, devido à redução do ciclo de vida dos produtos, entre outros fatores. No caso do Brasil, a abertura dos mercados e a busca pela internacionalização têm pressionado as empresas a procurarem formas alternativas de desenvolvimento tecnológico. Uma dessas formas tem sido a estratégia de alianças.

O resultado apresentado mostra que as empresas do setor eletroeletrônico pesquisadas desenvolveram capacidade tecnológica e de absorção por meio das alianças desenvolvidas, que possibilitaram a ampliação de sua base de conhecimento. As alianças estratégicas nas quais elas entraram tiveram papel importante nesse desenvolvimento.

Contudo a resposta encontrada para a questão apresentada neste artigo mostra também que o impacto dos fatores condicionantes, examinados na construção da capacidade tecnológica, é relativo, podendo ora auxiliar, ora limitar a competitividade internacional das empresas locais. De fato, elas ainda precisam de maior investimento no desenvolvimento de sua capacidade de absorção e na sua capacidade tecnológica para participarem ativamente do mercado internacional de forma mais competitiva.

Ficou patente na pesquisa que a participação nas alianças estratégicas pode acelerar o desenvolvimento da capacidade tecnológica das empresas; porém elas devem possuir capacidade de absorção inicial relacionada ao negócio tecnológico. Para tanto investimentos regulares são necessários, dentro de uma estratégia de médio e longo prazo, estratégia interna, desenvolvida pela própria empresa; de capacitação, via estabelecimento de alianças; e externa, por mediação de políticas governamentais mais robustas na área de apoio ao desenvolvimento de C\&T.

Outro fator importante é a participação ativa em programas governamentais, já existentes e futuros, de apoio à competitividade empresarial. Três das empresas pesquisadas consideraram que a utilização das vantagens protecionistas, advindas da Reserva de Mercado, foram estratégicas para o seu desenvolvimento, mostrando que a participação governamental pode ser fator positivo no desenvolvimento tecnológico, enquanto duas empresas consideraram que o período foi negativo para o crescimento verificado na empresa. Sugere-se que futuros estudos aprofundem as causas e as consequências da participação dessas empresas em programas governamentais no desenvolvimento da capacidade tecnológica e da competitividade internacional.

O presente estudo apresenta alguns limites. A validade externa do estudo pode ser considerada como limitada, visto que apenas cinco casos foram analisados. Consequentemente, os resultados não podem ser generalizados. Contudo deve ser mencionado que algumas das empresas estudadas são líderes em seus mercados. Esse é o caso da Inepar e da Stemac. Elas representam jogadores chave dentro de seus segmentos no Brasil.

Logo, várias conclusões podem ser aplicadas especificamente para seu segmento. Igualmente, Info e Aeroeletrônica são consideradas altamente representativas da realidade do mercado eletroeletrônico na área de software e aviônicos. A Info divide o mercado nacional com outra empresa, enquanto a Aeroeletrônica permanece a única empresa brasileira que continua em operação no seu segmento.

Finalmente, a pesquisa realizada por este estudo apresenta uma contribuição importante. Entre outros instrumentos, ela mostra que as alianças aceleram o desenvolvimento tecnológico; porém o estudo indica que uma estratégia de aliança deve ser, idealmente, utilizada apenas por empresas que possuam nível de capacidade de absorção suficiente para entender e incorporar a tecnologia que estão recebendo. Novas pesquisas em outros PRI, e envolvendo outros setores, poderão validar e consolidar os resultados apresentados neste estudo.

\section{Artigo recebido em 03.10.2007. Aprovado em 13.10.2008.}




\section{NOTAS}

\footnotetext{
${ }^{1}$ Países recentemente industrializados [PRI] - em inglês, newly industrialized countries. Essa definição será utilizada seguindo a discussão de Viotti (2002). De acordo com o autor, os PRI apresentam processos de inovação tecnológica diferentes dos PI. Os PRI devem preocupar-se com seus Sistemas Nacionais de Aprendizagem [SNA] diferentemente dos PI que desenvolvem políticas voltadas para seus Sistemas Nacionais de Inovação. Somente os SNA consideram o importante papel da difusão tecnológica no processo de inovação.

${ }^{2} \mathrm{O}$ padrão Telebrás foi desenvolvido para a padronização tecnológica de todos os fornecedores da Telebrás.
}

\section{REFERÊNCIAS BIBLIOGRÁFICAS}

Agência Estado. (2008, agosto 14). Abinee: investimento do setor eletroeletrônico deve atingir $R \$ 4,9$ bi. Recuperado em 14 novembro, 2008, de http://br.news.yahoo.com/s/14082008/25/tecnologiaabinee-investimento-setor-eletroeletronico-deve-atingir-r-4-9.html

Albuquerque, E. M. (1996). Sistema nacional de inovação no Brasil: uma análise introdutória a partir de dados disponíveis sobre a ciência e a tecnologia. Revista de Economia Política, 16(3), 56-72.

Argyris, C., \& Schön, D. (1978). Organizational learning: a theory of action perspective. New York: McGraw-Hill.

Arnold, E., Allinson, R., Muscio, A., \& Sowden, P. (2004). Making the best use of technological knowledge: a study of the absorptive capacity of Irish SMEs. Brighton: Technopolis.

Arocena, R., \& Sutz, J. (1999). Looking at national systems of innovation from the south [Mimeo]. Universidad de la Republica, Montevideo, Uruguay.

Arrow, K. J. (1962). The economic implications of learning by doing. Review of Economic Studies, 29(3), 155-173.

Associação Brasileira da Indústria Elétrica e Eletrônica. (2007). Avaliação setorial. Recuperado em 19 setembro, 2007, de http://www.abinee.org.br/abinee/decon/decon11.htm

Balbinot, Z. (2005). Building technological capability in Brazilian firms through alliances. Tese de doutorado, École des Hautes Études Commerciales, Université de Montréal, Montreal, Canadá.

Balbinot, Z., \& Bignetti, L. P. (2007). Technological capabilities of high technology firms in cross border alliances. In H. Sherif \& T. Khalil (Eds.). New directions in technology management (pp. 249-261). Oxford: Elsevier Science Publishing Company.

Bell, M. (1984). Learning and the accumulation of industrial technological capacity in developing countries. In K. Fransman \& M. King (Eds.). Technological capability in the third world (pp. 187-209). London: McMillan Press.

Bell, M., \& Pavitt, K. (1993). Technological accumulation and industrial growth: contrasts between developed and developing countries. Industrial and Corporate Change, 2(2), 157-210.

Bernardes, R. (2000). O arranjo produtivo da Embraer na região de São José dos Campos [Mimeo]. Instituto de Economia, Universidade Federal do Rio de Janeiro, Rio de Janeiro, RJ. 
Capdevielle, M., Cimoli, M., \& Dutrénit, G. (1997). Specialization and technology in Mexico: a virtual pattern of development and competitiveness? [Interim Report IR-97-016]. International Institute for Applied Systems Analysis, Laxenburg, Áustria.

Cassiolato, J., \& Lastres, H. (1999, June). Local, national and regional systems of innovation in the Mercosur. Proceedings of the DRUID's Summer Conference on National Innovation Systems, Industrial Dynamics and Innovation Policies, Rebild, Denmark, 16.

Chang, P. L., Hsu, C. W., \& Tsai, C. T. (1999). A stage approach for industrial technology development and implementation: the case of Taiwan's computer industry. Technovation, 19(4), 233-241.

Cohen, W., \& Levinthal, D. (1990). Absorptive capacity: a new perspective on learning and innovation. Administrative Science Quarterly, 35(1), 128-152.

Cooke, P., Uranga, M., \& Etxebarria, G. (1997). Regional innovation systems: institutional and organisational dimensions. Research Policy, 26(4-5), 475-491.

Costa, I., \& Queiroz, S. R. R. (2002). Foreign direct investment and technological capabilities in Brazilian industry. Research Policy, 31(8-9), 1431-1443.

Dahlman, C., \& Frischtak, C. (1990). National systems supporting technical advance in industry: the Brazilian experience. Brighton: University of Sussex/SPRU.

De Negri, J., \& Salerno, M. (Orgs.). (2005). Inovações, padrões tecnológicos e desempenho das firmas industriais brasileiras. Brasília: IPEA.

Dutrénit, G. B. (2001). Learning and knowledge management in the firm: from knowledge accumulation to strategic capabilities. Cheltenham: Edward Elgar.

Figueiredo, P. N. (2003b). Aprendizagem tecnológica e performance competitiva. Rio de Janeiro: FGV.

Figueiredo, P. N. (2003a). Learning, capability accumulation and firms differences: evidence from latecomer steel. Industrial and Corporate Change, 12(3), 607-643.

Freeman, C. (1987). Technology and economic performance: lessons from Japan. London: Pinter Publishers.

Garrette, B., \& Dussauge, P. (1995). Les stratégies d'alliance. Paris: Les Éditions d'Organisation.

Gilbert, M., \& Cordey-Hayes, M. (1996). Understanding the process of knowledge transfer to achieve successful technological innovation. Technovation, 16(6), 301-312.

Hamel, G. (1991). Competition for competence and inter-partner learning within international strategic alliances. Strategic Management Journal, 12(Special Issue), 83-103.

Hauser, G., Zen, A. C., \& Selao, D. C. (2007). A indústria eletrônica no Brasil e na China: um estudo comparativo e a análise das políticas públicas de estímulo à capacidade tecnológica do setor. Journal of Technology Management and Innovation, 2(3), 85-96.

Inkpen, A. (1996). Creating knowledge through collaboration. California Management Review, 39(1), $123-140$.

Instituto de Pesquisa Econômica Aplicada. (2008). Políticas sociais - acompanhamento e análise. $\begin{array}{lllll}\text { Recuperado em } & 17 & \text { novembro, }\end{array}$ http://www.ipea.gov.br/sites/000/2/publicacoes/bpsociais/bps_15/16_completo.pdf

Katz, J. (1976). Importación de tecnología, aprendizaje y industrialización dependiente. Mexico: Fondo de Cultura Económica. 
Katz, J. (1998). Structural reforms and technological behaviour: the sources and nature of technological change in Latin America in the 1990s [Mimeo]. ECLAC/UN, Santiago de Chile.

Katz, J. (2000). Pasado y presente del comportamiento tecnológico de América Latina [Serie Desarrollo Productivo $N^{\circ}$ 75]. Santiago de Chile: Red de Reestructuración y Competitividad, División de Desarrollo Productivo y Empresarial.

Katz, J. (2001). Structural reforms, productivity and technological change in Latin America. New York: United Nations Publications.

Katz, J., \& Kosacoff, B. (1998). Aprendizaje tecnológico, desarrollo institucional y la microeconomía de la sustitución de importaciones. Desarrollo Económico Revista de Ciencias Sociales, 37(148), 483-502.

Kharbanda, V. P., \& Jain, A. (1997). Indigenization and technological change at the firm level - the case of the black and white TV picture. Technovation, 17(8), 439-456.

Killing, P. (1980). Technology acquisition: license agreement or joint venture. Columbia Journal of World Business, 15(3), 38-46.

Kim, L. (1997). Imitation to innovation: the dynamics of Korea's technological learning. Boston: Harward Business School Press.

Kim, L. (2002). The dynamics of technological learning in industrialization. International Social Science Journal, 53(168), 297-308.

Knight, P., \& Marques, R. (2008). Closing the tecnology gap. In J. Haar \& J. Price (Eds.). Can Latin America compete? Confronting the challenges of globalization (pp. 99-120). Florida: Palgrave McMillan Press.

Kumar, V., Kumar, U., \& Persaud, A. (1999). Building technological capability through importing technology: the case of Indonesian manufacturing industry. Journal of Technology Transfer, 24(1), 81-96.

Lall, S. (1982). Developing countries as exporters of technology. London: Macmillan.

Lall, S. (1985). Trade in technology by a slowly industrializing country: India. In N. Rosenberg \& C. Firschtak (Eds.). International technology transfer: concepts, measures, and comparisons (pp. 45-76). New York: Praeger.

Lall, S. (1992). Technological capabilities and industrialisation. World Development, 20(2), 165-186.

Leonard-Barton, D. (1995). Wellsprings of knowledge: building and sustaining the sources of innovation. Boston: Harvard Business School Press.

Marques, R., \& Oliveira, L. G. (2006, October). Sectoral system of innovation in Brazil: reflections about the accumulation of technological capabilities experienced by SME suppliers to the aeronautic industry and the role of research institutions, national and foreign buyers. Recuperado em 12 dezembro, 2006, de http://www.globelicsindia2006.org/sessions.php

Miles, M., \& Huberman, M. (1994). Qualitative data analysis: an expanded source book. California: Sage Publications, Inc.

Ministério do Desenvolvimento, Indústria e Comércio Exterior. (n.d.). Ações setoriais para o aumento da competitividade da indústria brasileira. Recuperado em 19 setembro, 2007, de http://www2.desenvolvimento.gov.br/sitio/publicacoes/desProducao/desProducao.php 
Nelson, R., \& Rosenberg, N. (1993). Technical innovation and national systems. In R. Nelson (Ed.). National innovation systems: a comparative study (pp. 3-22). Oxford: Oxford University Press.

Nonaka, I., \& Takeuchi, H. (1996). A theory of organizational knowledge creation. International Journal of Technology Management, 11(7/8), 833-845.

Panda, H., \& Ramanathan, K. (1996). Technological capability assessment of a firm in the electricity sector. Technovation, 16(10), 561-588.

Sercovitch, F. C. (1988). Domestic learning, international technology flows and the world market: new perspectives for the developing countries [Working Paper $\mathrm{N}^{\circ}$ 189/ WEP 2-22]. International Labour Organisation, Geneva, Suíça.

Simon, H. A. (1945). Administrative behavior: a study of decision-making processes in administrative organizations. New York: Free Press.

Tavares, W. M. L. (2001). A indústria eletrônica no Brasil e seu impacto sobre a balança comercial. $\begin{array}{lllll}\text { Recuperado em } & 15 & \text { Novembro, } & \text { 2008, }\end{array}$ http://apache.camara.gov.br/portal/arquivos/Camara/internet/publicacoes/estnottec/pdf/108604.pdf

Terra. (2008, agosto 27). Brasil: internautas batem recorde em número e tempo de navegação. Recuperado em 27 agosto, 2008, de http://tecnologia.terra.com.br/interna/0,,OI3139143EI4802,00-Brasil+internautas+batem+recorde+em+numero+e+tempo+de+navegacao.html

Velho, L., \& Saenz, T. W. (2002). R\&D in the public and private sector in Brazil: complements or substitutes? [Discussion Paper 2002-8]. UNU/INTECH, Maastricht. Recuperado em 15 janeiro, 2003, de http://www.intech.unu.edu/publications/discussion-papers/2002-8.pdf

Viotti, E. (2002). National learning systems: a new approach on technological change in late industrializing economies and evidences from the cases of Brazil and South Korea. Technological Forecasting e Social Change, 69(7), 653-680.

Westphal, L. E., Kim, L., \& Dahlman, C. J. (1985). Reflections on the Republic of Korea's acquisition of technological capability. In N. Rosenberg \& C. Firschtak (Eds.). International technology transfer: concepts, measures, and comparisons (pp. 167-221). New York: Pergamon Press.

Yin, R. (1994). Case study research: design and methods. California: Sage Publications, Inc. 